\title{
Increase of Enamel Hardness Score after Cow Milk Immersion of Demineralized Tooth: An In vitro Study
}

\author{
${ }^{1}$ Yendriwati, ${ }^{2}$ Rizka M Sinaga, ${ }^{3} \mathrm{D}$ Dennis
}

\begin{abstract}
Aim: To investigate the difference of enamel hardness score on tooth immersed in artificial saliva and cow milk.

Materials and methods: The present study was an experimental laboratory with pre- and post-test design. Thirty-two maxillary first premolars were collected and randomly divided into two groups, with 16 samples each immersed in artificial saliva and cow milk. Samples were immersed in an orange flavored soft drink for 5 minutes before exposing to cow milk (group 1) or artificial saliva (group 2) for 5 minutes twice a day until day 3 . Enamel hardness score was measured as follows: pretreatment, post demineralization stage and posttreatment at day 1 and day 3 by Micro Vickers hardness tester. Data were analyzed using paired t-test and one way analysis of variance (ANOVA).
\end{abstract}

Results: There was a significant difference $(p$ value $=0.000)$ on enamel hardness score of group 1 at day 1 (324.39 \pm 20.35 VHN) and day $3(354.80 \pm 21.09 \mathrm{VHN})$ as well as group 2 at day 1 $(308.06 \pm 15.94 \mathrm{VHN})$ and day $3(322.18 \pm 16.94 \mathrm{VHN})$. Tooth enamel hardness on group 1 was significantly different to group 2 both at day $1(p$ value $=0.018)$ and day $3(p$ value $=0.000)$.

Conclusion: These results suggest that artificial saliva and cow milk can increase the enamel hardness score. However, the efficacy of cow milk to augment the tooth enamel hardness is much higher than that of artificial saliva.

Clinical significance: Can be used as a primary advice to the public in as precautionary measures and inhibiting tooth enamel damage from acidic drinks.

Keywords: Artificial saliva, Cow milk, Enamel hardness, Remineralization.

How to cite this article: Yendriwati, Sinaga RM, Dennis D. Increase of Enamel Hardness Score after Cow Milk Immersion of Demineralized Tooth: An In Vitro Study. World J Dent 2018;9(6):439-443.

Source of support: Nil

Conflict of interest: None

\section{INTRODUCTION}

Soft drinks mainly have acidic $\mathrm{pH}$ lower than four that may cause demineralization on tooth enamel. ${ }^{1}$ Demineralization is a process of enamel dissolution

\footnotetext{
${ }^{1-3}$ Department of Oral Biology, Faculty of Dentistry, Universitas Sumatera Utara, Medan, North Sumatera, Indonesia

Corresponding Author: Yendriwati, Department of Oral Biology, Faculty of Dentistry, Universitas Sumatera Utara, Medan, North Sumatera, Indonesia, Phone: 061 8216131, e-mail: drg.yendriwati@ gmail.com
}

when the release of hydroxyapatites occurs leading to micropores formation on enamel surface. ${ }^{2}$ Enamel consists of hydroxyapatite $\left(\mathrm{Ca}_{10}\left(\mathrm{PO}_{4}\right)_{6}(\mathrm{OH})_{2}\right)$ and fluorapatite $\left(\mathrm{Ca}_{10}\left(\mathrm{PO}_{4}\right)_{6} \mathrm{~F}_{2}\right)$. Hydroxyapatite has critical pH 5.5 whereas fluoride apatite falls to $\mathrm{pH} 4.5^{3}$

Demineralization and remineralization process is associated with tooth enamel surface hardness. Hardness is defined as a resistance of solid matter to penetration. ${ }^{4}$ Tooth hardness is influenced by the level of phosphate and calcium of enamel, called hydroxyapatite, in which the amount of hydroxyapatite relates to the thickness of enamel. ${ }^{5}$

Owen et al. found that beverages with acidic $\mathrm{pH}$ such as sport and energy drinks, as well as orange juice initiated enamel dissolution by measuring the percentage of tooth enamel weight loss. To decrease or prevent the risk of dental erosion can be done by (a) avoiding the direct contact of acidic foods or drinks on tooth surface thus discontinuing the process of tooth demineralization; (b) applying remineralizing agents immediately after consuming foods or drinks by fluoride mouth rinse, and (c) drinking milk to accelerate remineralization process. ${ }^{6}$

Usually, the saliva buffering capacity neutralizes the low $\mathrm{pH}$ in the oral cavity when the acidic condition is present and increases saliva $\mathrm{pH}$ followed by remineralization. Remineralization is a process of restoring phosphate and calcium ions on tooth enamel surface when oral cavity $\mathrm{pH}$ returns to neutral. ${ }^{7}$ During remineralization, it requires minerals such as calcium, phosphate, magnesium, and fluoride to promote tooth calcification. Calcium and phosphate are commonly found in cow milk and its product (e.g., yogurt and cheese), soy milk, salmon fish and broccoli, whereas water, seafood, yogurt, and cheese are a source of fluoride. ${ }^{8}$

Cow milk can protect the tooth from erosion, particularly if consumed immediately after acids intake. It has been shown to enhance tooth enamel remineralization due to casein, calcium, and phosphate. ${ }^{1,9}$ Amoras et al. found that cow milk was able to maintain demineralization process from hydrochloric acid toward the advanced stage, which observed in an increased enamel surface hardness. ${ }^{9}$ Lachowski et al. investigated that cow milk could increase tooth enamel surface hardness, which decreases the potential of dental erosion. The reduction of enamel surface hardness of orange juice-immersed tooth was higher than of orange juice-immersed tooth followed by milk immersion. ${ }^{1}$ 
The aim of this study was to investigate the difference of tooth enamel hardness score after artificial saliva or cow milk immersion of demineralized tooth.

\section{MATERIALS AND METHODS}

This study was an experimental laboratory with pre- and post-test design conducted in University of Negeri Medan Mechanical Engineering laboratory and Biology laboratory. This study was approved by the Medical Research Ethics Committee, Faculty of Medicine, University of Sumatera Utara, no. 312/KOMET/FK USU/2016 on April 14, 2016.

Inclusion criteria were the extracted maxillary first premolar collected from patients age of 17-30 years for orthodontic purpose with normal size, shape, and tooth structure, and the crown must be intact. Exclusion criteria were caries tooth or erosion, attrition, and abrasion tooth, dental filling, a tooth with endodontic treatment, cracked tooth, fracture, necrosis, and whitened tooth. Samples were thirty-two maxillary first premolar extracted from patients that fulfill the inclusion and exclusion criteria.

The tooth was thoroughly cut at the cementoenamel junction that subsequently separate the root and crown part. Palatal surface of the crown was coated with nail varnish, then was implanted in acrylic (Fig. 1). Each tooth was randomly numbered and divided into two groups. Tooth enamel hardness was measured before sample treatment.

All samples were immersed in an orange flavored soft drink for 5 minutes to demineralize teeth. Group 1 was stored in cow milk ( $\mathrm{pH}$ 6.5) for 5 minutes twice a day at 11.00 and 17.00. Group 2 was stored in artificial saliva ( $\mathrm{pH}$ 6.8) for 5 minutes twice a day at 11.30. Artificial saliva was produced in University of Gadjah Mada Chemical Laboratory. Later, at 17.30 samples were immersed in aquabidest and incubated at $37^{\circ} \mathrm{C}$. The experiment was performed for 3 days.

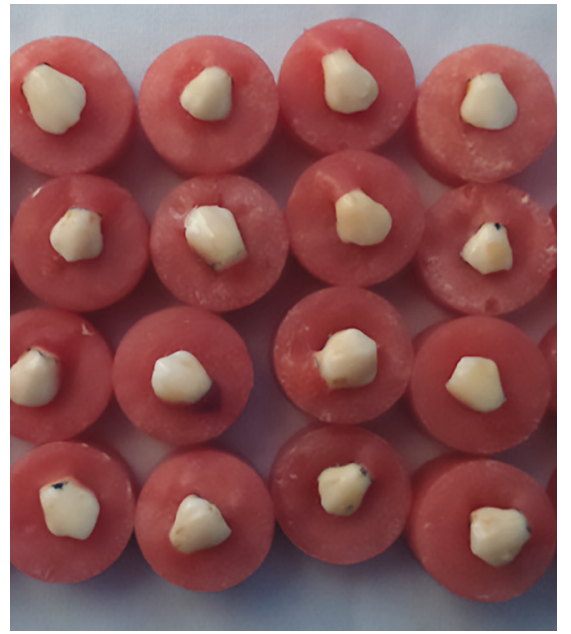

Fig. 1: Tooth embedded in acrylic
Enamel hardness score of samples on pre- and postacid immersion was assessed on day 1 . Hardness score of tooth immersed in cow milk and artificial saliva on day 1 was measured on day 2, whereas tooth immersed on day 3 was measured on day 4 using Micro Vickers hardness tester with load $100 \mathrm{~g}$ for 15 seconds for three times (Fig. 2).

Data were analyzed using paired t-test and one way ANOVA with post hoc test.

\section{RESULT}

Table 1 shows the average of enamel hardness scores on pre- and posttreatment including orange flavored soft drink, cow milk, and saliva immersion. Enamel hardness score is decreased in all samples post acid immersion compared to pretreatment samples. However, the increased enamel hardness score is shown at day 1 and day 3 posttreatment in both groups compared with post acid treatment.

Paired t-test analysis shows that enamel hardness score in cow milk-immersed samples at day 3 is significantly higher than samples at day 1 ( $p$ value $<0.05$ ) (Table 2 ).

Enamel hardness score in artificial saliva treated group at day 3 is significantly increased compared to day 1 analyzed by paired t-test ( $p$ value $<0.05$ ) (Table 3 ).

One way ANOVA was used to determine the difference of enamel hardness score after cow milk and artificial saliva immersion in each time course with a level of significance $p$ value $=0.000(p$ value $<0.05)$. There is a significantly different hardness score of tooth enamel soaked in cow milk and artificial saliva at each time point. Additionally, to determine which group is significantly different from the others, LSD post hoc test was used (Table 4).

\section{DISCUSSION}

Enamel hardness varies in type and location of the measured tooth. Chemical composition and enamel thickness

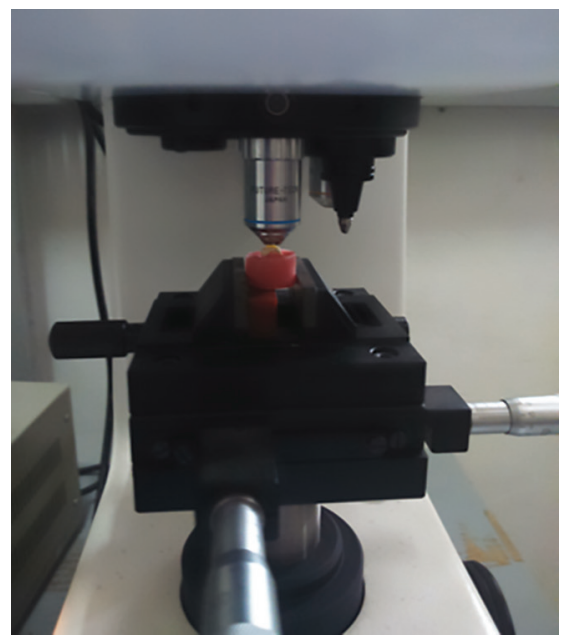

Fig. 2: Hardness tester 
Enamel Hardness Score After Cow Milk Immersion

Table 1: The average of enamel hardness score on pre- and post-treatment (acid, cow milk, and saliva) at day 1 and day 3

\begin{tabular}{lll}
\hline Type of treatment & Group I (cow milk) $X \pm S D(V H N)$ & Group II (artificial saliva) $X \pm S D(V H N)$ \\
\hline Pretreatment & $376.23 \pm 16.94$ & $373.22 \pm 15.08$ \\
Post demineralization & $309.62 \pm 18.44$ & $301.18 \pm 15.44$ \\
Remineralization agent treatment day 1 & $324.39 \pm 20.35$ & $308.06 \pm 15.94$ \\
\hline Remineralization agent treatment day 3 & $354.80 \pm 21.09$ & $322.18 \pm 16.94$ \\
\hline
\end{tabular}

Table 2: Difference of enamel hardness score after cow milk immersion at day 1 and day 3 analyzed by paired t-test

\begin{tabular}{llll}
\hline Time of immersion & $X \mp S D(V H N)$ & $\bar{\Delta} X(V H N)$ & Sig. ( $p$ value $)$ \\
\hline Day 1 & $324.39 \pm 20.35$ & 30.41 & $0.000^{*}$ \\
Day 3 & $354.80 \pm 21.09$ & & \\
\hline &
\end{tabular}

Table 4: LSD test showing the enamel hardness score after cow milk and artificial saliva immersion at day 1 and day 3

\begin{tabular}{lllll}
\hline & \multicolumn{3}{c}{ Artificial saliva } \\
\cline { 2 - 5 } Cow milk & \multicolumn{2}{c}{ Day 1 } & \multicolumn{2}{c}{ Day 3 } \\
\hline \multirow{4}{*}{ Day 1} & $\Delta \mathrm{X}(\mathrm{VHN})$ & Sig. ( $p$ value $)$ & $\Delta \mathrm{X}(\mathrm{VHN})$ & Sig. ( $p$ value $)$ \\
Day 3 & 16.33 & $0.018^{*}$ & 2.21 & 0.740 \\
\hline
\end{tabular}

*level of significance, $p$ value $<0.05$

may take part in each tooth. The present study was done to quantitate enamel hardness on buccal surface and the representative data were subsequently selected for each measurement. Initial hardness measurement (Table 1) shows the distinct values of standard deviation in every group. Palti et al. found the enamel hardness score in pre-treatment group ranges from 367.13 to $399.97 \mathrm{VHN} .^{10}$ Meanwhile, the present study showed the average value ranging from 358.48 to 390.58 VHN. Palti selected premolar 4-10 years after eruption as a model sample, whereas this study used premolar from a patient in the age of 17-30 years implying that the tooth has erupted for 6-19 years.

The tooth period in the oral cavity is one of the factors affecting the enamel hardness. Enamel surface on maturation stage post-eruption eventually contact to saliva and the dynamic process between demineralization and remineralization occurs during and after tooth eruption. ${ }^{10}$

Samples were immersed in an orange flavored soft drink for 5 minutes and the hardness score was measured. The decreased enamel hardness score after acid immersion was observed, indicating that orange flavored soft drink might reduce enamel hardness. The $\mathrm{pH}$ value of the solution used in this study (3.6) is much lower than the critical $\mathrm{pH}$ of hydroxyapatite (5.5). Direct contact between hydroxyapatite and solution with low $\mathrm{pH}(<5.5)$ leads to enamel mineral dissolution that may influence enamel hardness. ${ }^{6}$

There are some factors affecting the rate of enamel dissolution, such as acidity level $(\mathrm{pH})$, concentration, mineral ion composition, and saliva flow, saliva buffering capacity, diet (quantity and frequency of carbohydrate intake), and tooth structure. ${ }^{6,11}$
Table 3: Difference of enamel hardness score after artificial saliva immersion at day 1 and day 3 analyzed by paired t-test

\begin{tabular}{llll}
\hline Time of immersion & $X \mp S D(V H N)$ & $\bar{\Delta} X(V H N)$ & Sig. ( $p$ value) \\
\hline Day1 & $308.06 \pm 15.94$ & \multirow{2}{*}{14.12} & $0.000^{*}$ \\
Day 3 & $322.18 \pm 16.94$ & & \\
\hline
\end{tabular}

*level of significance, $p$ value $<0.05$

Furthermore, samples were immersed in cow milk (group 1) and artificial saliva (group 2). Cow milk has approximately $\mathrm{pH} 6.5$ and artificial saliva has $\mathrm{pH} 6.8$. Enamel hardness score was increased both at day 1 and day 3 , due to the presence of the remineralization process on the tooth. Remineralization is a process to restore mineral ions into hydroxyapatite structure. ${ }^{7}$ Adequate saliva flow rate, the presence of calcium, phosphate, as well as fluoride, and neutral $\mathrm{pH}$ of the oral cavity are the factors involved in remineralization. ${ }^{11}$ Preserved foods and high glucose diet may predispose to inadequate remineralization. Therefore, remineralization activity needs to boost to maintain enamel strength by providing mineralization agents that release calcium and phosphate ions to enamel surface, calculus-free, resistance to lower $\mathrm{pH}$ (acid), stimulating remineralization in saliva and appropriate for a patient with xerostomia. ${ }^{12}$

Table 2 shows there is a significant difference ( $p$ value $<0.05$ ) of enamel hardness score in group 1 (cow milk) at day 1 and day 3 analyzed by paired t-test. According to these results, it indicates that cow milk could increase enamel hardness at day 1 and get much higher at day 3 . Calciums and phosphors in cow milk play an important role during remineralization to increase enamel hardness. In contrast, Amoras et al. found that the enamel hardness was increased but not significant in cow milk-immersed tooth which was presoaked in $\mathrm{HCl}$ before milk immersion. ${ }^{9}$ The tooth immersion was performed for 4 times 1 minute each, which was rather shorter in time. Also, different mineral level in cow milk may affect the result.

Enamel hardness score in cow milk-immersed tooth at day 3 is higher than that at day 1 with the difference as $30.41 \mathrm{VHN}$. The longer and more frequent the enamel is exposed to calcium and phosphor containing beverages, the more minerals the enamel takes up so that may raise the hardness of enamel.

Milk is a cellular emulsion mainly containing casein that is composed of a thousand protein molecules bound to calcium and phosphate. ${ }^{13}$ Drinking milk immediately after tooth exposed to acid is a good alternative because of its ability to protect 
the tooth from erosion. Milk acts as a remineralization agent, as well as increases mineral deposit and organic material on the enamel surface, and forms a protective film. This film is associated with casein adsorption on the surface of enamel to reduce the dissolved hydroxyapatite crystals and to prevent ions discharge. ${ }^{1}$ High calcium beverages show the reduced erosion formation and increase remineralization. Not only to modify the potency of erosion, but the addition of calcium may also alter the basic nature of beverages such as taste and color. Therefore, drinking milk or any others with natural calcium source is preferable to consume. ${ }^{9}$

Carbohydrate in cow milk is composed of $80 \%$ lactose. Lactose is fermented by bacteria in the oral cavity to be lactic acid, which can lower $\mathrm{pH}$ into 6.0. This carbohydrate has potentially low cariogenicity in a normal condition. ${ }^{14}$ However, for particular circumstances, milk may cause caries in children if consumed using a bottle during sleeping time. The decreased saliva flow rate is associated with the bottle caries in children that reduce the saliva neutralization capacity. When the kid is falling asleep, the oral cavity is overwhelmed with milk that eventually immerses the teeth leading to prolonged fermentation time of carbohydrate. The fermented carbohydrate produces acid to initiate enamel demineralization so that caries may occur. ${ }^{15}$

Drinking milk from a bottle at night is acceptable as long as the kids must brush their teeth before sleep. Milk for daily needs may reduce $\mathrm{pH}$ on plaque 10 minutes after drinking (6.79) due to fermentation of lactose in the milk and yet, this $\mathrm{pH}$ begins to rise 20 minutes afterward as peptides and amino acids produced by the hydrolysis of casein may increase $\mathrm{pH}$ on plaque and prevent the tooth to demineralize. ${ }^{14}$ Fermentation of lactose in oral cavity can be dismissed by gargling with water for 5 min after drinking milk.

Paired t-test in artificial saliva groups (Table 3) shows that there is a significant difference $(p$ value $<0.05)$ of enamel hardness score at day 1 and day 3. Hardness score at day 3 is much higher than that at day 1 as much as $14.12 \mathrm{VHN}$.

Several mechanisms involved in the protective function of saliva against erosion that is first, the direct action of saliva against the agent of erosion by liquefying, cleansing, neutralizing, and buffering of saliva. Secondly, organic components of saliva form a thin pellicle on enamel surface that may act to defend from direct contact between acid and tooth surface, thus affecting the dissolution level of tooth hard tissue. Thirdly, the existence of calcium and phosphate ions in saliva can become natural resources to a new crystal formation. ${ }^{16}$ Those functions mentioned above indicate that saliva has a potential ability to increase enamel hardness score as a result of remineralization.

This study shows that there is a difference of enamel hardness on tooth-immersed cow milk and artificial saliva in each time of immersion. According to one way ANOVA test, there is a difference of hardness score in each time point of all groups. LSD test (Table 4) shows the significant difference of tooth enamel hardness in cow milk-treated group compare with the artificial saliva-treated group at day 1 and in cow milk-treated group compare with an artificial saliva-treated group at day 3 ( $p$ value $<0.05$ ). The average of hardness score difference between cow milk and the artificial salivatreated group at day1 is $16.33 \mathrm{VHN}$, whereas at day 3 is $32.62 \mathrm{VHN}$.

According to those results, cow milk increases the enamel hardness much higher than artificial saliva does. Distinct calcium and phosphor contents in those two sources may affect remineralization so the enamel hardness score is also different in those groups. Moreover, milk, but not artificial saliva, contains casein that is rapidly adsorbed onto enamel surface to raise enamel resistance against acid. ${ }^{17}$

The limitation of the study was the results of tooth enamel hardness were different from the initial hardness before demineralization. This may be due to insufficient soaking of the samples, so it is necessary to add immersion days or by mixing cow's milk and artificial saliva to simulate the real oral conditions.

\section{CONCLUSION}

Cow milk has the better capability to raise the enamel hardness than artificial saliva does.

It can be used as a primary advice to the public in as precautionary measures and inhibiting tooth enamel damage from acidic drinks. Both cow milk and artificial saliva may enhance the enamel hardness.

\section{REFERENCES}

1. Lachowski KM, Ferreira D, de Oliveira TA, Sobral MAP. Effect of the mixture of coffee or chocolate to milk in the progression of des-remineralization of tooth enamel - an in vitro study. Braz Research in Pediatric Dent and Integrated Clinic 2014;14(3):183-190.

2. Miller KR. Remineralization strategies. http://www.rdhmag. com/articles/print/volume-26/issue7/feature/remineralization-strategies.html (8 October 2015).

3. Yamamoto ETC, Vanderlei A, Amaral R, Nicolo RD, da Rocha JC, de Araujo MAM. Influence of three types of drinks on the surface of human dental enamel: in vitro study. Rev GauchaOdontol 2013;61(1):42.

4. McCabe JF, Walls AWG. Bahankedokterangigi. AlihBahasa. Sunarinstyas S, Mustaqimah DN. Jakarta: EGC, 2015: 19-20. 
5. Gutierrez-Salazar MDP, Reyes-Gasga J. Microhardness and chemical composition of human tooth. Material Research 2003;6(3):367-373.

6. Owens BM, Malette JD, Phebus JG. Effect of carbonated cola beverages, sports and energy drinks and orange juice on primary and permanent enamel dissolution. Austin J Dent 2014;1:1-2.

7. Widyaningtyas V, Rahayu YC, Barid I. Analisispeningkatanremineralisasi enamel gigisetelahdirendamdalamsusukedelaimurni (Glycine max (L.) merill) menggunakan scanning electron microscope (SEM). J PustakaKesehatan 2014;2: 258-261.

8. Stegeman CA, Davis JR. The dental hygienist's guide to nutritional care. 3 th ed., Missouri: Saunders Elsevier, 2010:146.

9. Amoras DR, Corona SA, Rodrigues Jr AL, Serra MC. Effect of beverages on bovine dental enamel subjected to erosive challenge with hydrochloric acid. Brazilian dental journal. 2012;23(4):367-372.

10. Palti DG, Machado MAAM, Silva SMB, Abdo RCC, Lima JEO. Evaluation of superficial microhardness in dental enamel with different eruptive ages. Braz Oral Res, 2008;22(4):313-314.
11. Collin FM. Treatment options for tooth discoloration and remineralization. Pennwell, 2008:5.

12. Hemagaran G, Neelakantan P. Remineralization of the tooth structure-the future of dentistry. Int J of Pharm Tech Research 2014;6(2):487-491.

13. Davari AR, Kazemi ARD, Ataei E, Vatanpour M, Abdollahi $\mathrm{H}$. Effects of bleaching and remineralising agents on the surface hardness of enamel. J Dent Shiraz Univ Med Scien 2012;13(4):157-158.

14. Telgi RL, Yadav V, Telgi CR, Boppana N. In vivo dental plaque $\mathrm{pH}$ after consumption of dairy products. General Dentistry 2013.56-57.

15. Zafar S, Harnekar SY, Siddiqi A. Early childhood caries: etiology, clinical considerations, consequences andand management. International Dentistry SA 2009;11(4):24-36.

16. Wang X, Mihailova B, Klocke A, Heidrich S, Bismayer U. Effect of artificial saliva on the apatite structure of eroded enamel. Internatinal J of Spectroscopy 2011;2011

17. Reema SD, Lahiri PK, Roy SS. Review of casein phosphopeptides-amorphous calcium phosphate. The Chinese Journal of Dental Research, 2014;17(1):7-14. 